\title{
Experimental Study on Friction Coefficient and Stress Loss of Retard-bonded PC Steel Strand
}

\author{
Yue Ma ${ }^{1, a}$, Zhan-fei Wang ${ }^{2, b^{*}}$ and Shao-peng Cao ${ }^{3, c}$ \\ ${ }^{1}$ Applied Technology College of Dalian Ocean University, Dalian 116300, China \\ ${ }^{2}$ School of the Transportation Engineering, Shenyang Jianzhu University, Shenyang 110168 , \\ China \\ ${ }^{3}$ School of the Civil Engineering, Shenyang Jianzhu University, Shenyang 110168, China

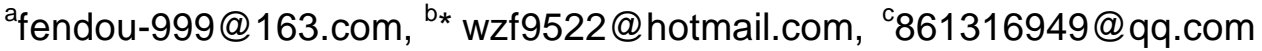

\begin{abstract}
Keywords: Retard-bonded PC Steel Strand; Retarder; Curing degree; Friction coefficient; Stress loss Abstract. In order to verify the influence of curing degree of retarded binder on the friction coefficient of retarded-bonded PC steel strand, 3 PC beams with $3300 \mathrm{~mm}$ in length and $300 \times 400$ cross-section is manufactured and 3 retard-bonded PC steel strands in straight-through arrangement at each PC beam is set. According to different retarder curing degree, tensile test of retard-bonded PC steel strands is carried out in batches with each batch of 3 PC steel strands. During the curing process of the retarder, long-term measurement of pre-stress loss of the PC steel strands has been carried out too. The experimental results showed that: 1) Under the same retarder curing degree, friction coefficient of PC steel strand would gradually decrease with the increases of tensile force. 2) As stress of PC steel strands reached control stress, the friction coefficient would gradually increase with the increase of retarder hardness. And when shore scleroscope hardness of retarder reached the value of 83.1, friction coefficient $\kappa$ of the PC steel strands increased to 0.5384. 3) The stress loss of PC steel strands was large upon completion of tensioning. The stress loss would decline gradually with the curing time increasing, and would tend to stable after 109 days.
\end{abstract}

\section{Introduction}

Retard-bonded pre-stressed concrete, as a new PC structure, has the advantages of convenient construction similar to un-bonded pre-stressed concrete structure, and also, it has force-transfer mechanism similar to bonded pre-stressed concrete structure after curing of retarder ${ }^{[1]}$. The functional mechanism: the retarded-bonded materials with certain coating thickness outside of PC steel strand, inside of HDPE cover is applied (as shown in Fig.1), this material would provide mobility for PC steel strand during tensioning applicable period, would generate binding strength between PC steel strand and HDPE cover after perfectly curing. Because of the HDPE cover surface is crushed into screw-thread. Retard-bonded steel strand would form the same transmission mechanism with bonded PC structure.

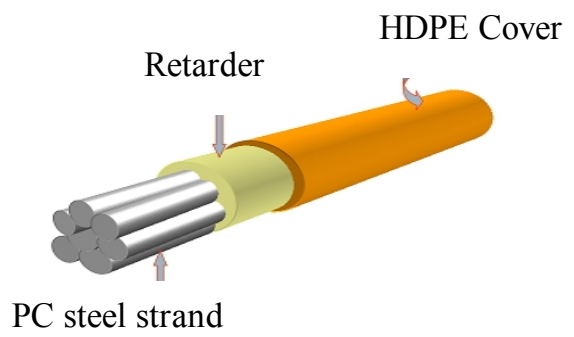

Fig.1 Retard-bonded pre-stressed steel strands

In recent years, retard-bonded pre-stressed concrete structure has been widely applied in our country. However, it would usually take 1-2 years for manufacturing, tensioning, retarder perfectly curing of retard-bonded PC steel strand. During that process, retarder would turn into solid state with certain bonding strength from flexible liquid state. It would be divided into two stages from engineering perspective, i.e. tensioning application period and curing period (as shown in Fig.2) ${ }^{[2]}$. It would have 
great influence of the tensioning occasion and the frictional loss for construction quality of retard-bonded PC structure ${ }^{[3-6]}$.

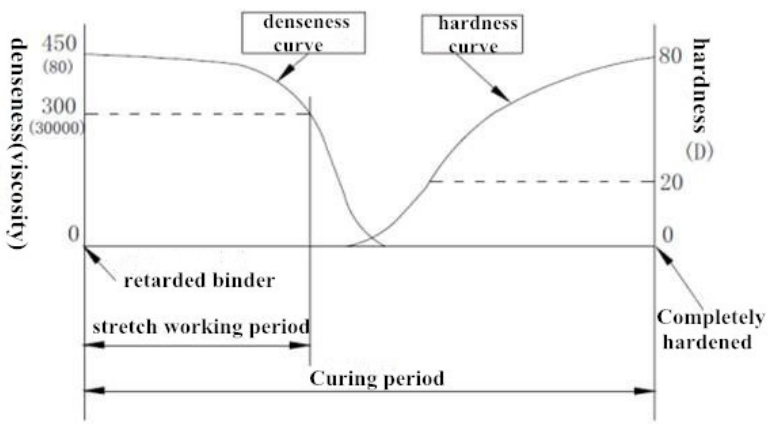

Fig. 2 The relationship of curing degree and curing time of Retarded binder

In this paper, the $3 \mathrm{PC}$ beams with $3300 \mathrm{~mm}$ in length and $300 \times 400$ cross-section is manufactured and 3 retard-bonded pre-stressed steel strands in straight-through arrangement at each PC beam is set. According to different retarder curing degree, tensile test of retard-bonded PC steel strands is carried out in batches with each batch of 3 PC steel strands and stress loss of was measured. During the curing process of the retarder, long-term measurement of pre-stress loss of one of the PC steel strands has been carried out, too. Through experimental results, it is verified the influence of retarder curing degree during tensioning and after tensioning on stress loss of the PC steel strands.

\section{Test outline}

\section{Test specimens}

These 3 test specimens were manufactured using C50 concrete; the length of specimens for friction coefficient tests is $3300 \mathrm{~mm}$, the cross-section of specimens is $300 \times 400 \mathrm{~mm}$. These 3 retard-bonded PC steel strands along straight-through is arranged in each specimen. Retard-bonded PC beam test specimens shown Fig.3.
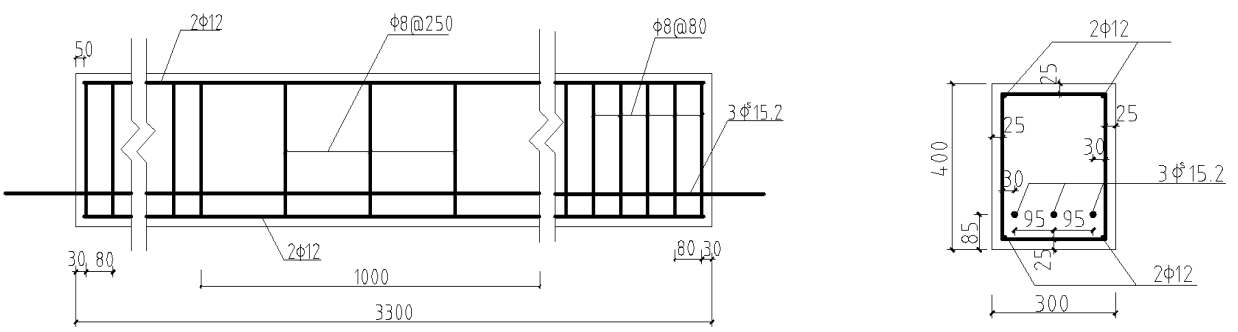

Fig. 3 Retard-bonded PC beam test specimens

\section{Test method}

In order to study the influence of retarder curing degree to PC steel strands friction coefficient during tensioning, according to different curing degree, the PC steel strands were tensioned for 3 times with 3 bars at each time. When stress of PC steel strands reached control stress, stress frictional loss was measured. During tensioning retard-bonded PC steel strands, the followings shall be installed in order at tensioning end: pressure-bearing pad with $300 \times 400 \times 14$, pressure loading sensor, pressure-bearing pad with $150 \times 150 \times 20$, cross-core hydraulic jack, $150 \times 150 \times 20$ pressure-bearing pad tool anchor; the followings shall be installed anchor end: pressure-bearing pad, pressure sensor, sub plate and anchorage device. Anchorage device schematic and collecting device during test were as shown in Fig. 4. Tensile force of retard-bonded PC steel strands tensioning end and anchor end would be measured by electronic static strain gauge which connected the two sensors.

During the test, $250 \mathrm{kN}$ cross-core hydraulic jack was adopted to tension the PC steel strands and the pre-stress applied on the tensioning end was controlled by electronic type pressure sensor. During tensioning, loading process was controlled by the sensor on tensioning end with $20 \mathrm{kN} /$ level and 
loading period of $30 \mathrm{~s}$ for each loading level. The load shall be held for $1 \mathrm{~min}$ and the readings of the sensors on tensioning end and anchor end shall be recorded in the mean time. When tensile force applied on PC steel strands reached $195.3 \mathrm{kN}$ that was reached the PC steel strands control stress of $0.75 f_{p t k}$, the load shall be held for $5 \mathrm{~min}$, the readings of the sensors shall be recorded.

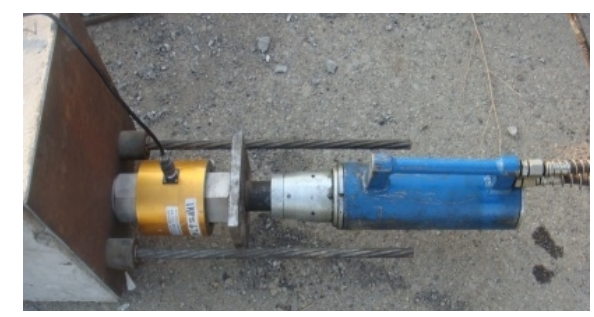

( a ) Tensioning device

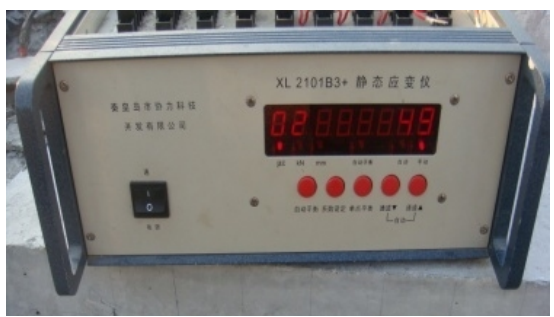

( b ) Collecting device of electronic static strain gauge

Fig. 4 Tensioning schematic and collecting device

Under straight steel strands layout, calculation fortmula for friction coefficient $k$ as follow:

$$
k=\frac{-\ln \left(F_{2} / F_{1}\right)}{x}
$$

Where, $\mathrm{x}$ represents length of straight retard-bonded PC steel strand; $F_{2}$ is anchor end force $(\mathrm{kN}) ; F_{1}$ is tensioning end force $(\mathrm{kN})$.

\section{Retarder property of retard-bonded PC steel strands at different curing time}

Retarder property variations of retarded-bonded PC steel strands at different curing time were listed in Table 1. Therein tensioning shore scleroscope hardness was measured on the samples taken from the same batch of retard-bonded PC steel strands. The values were measured by shore scleroscope durometer and the data represented the curing degree of retarder. When hardness of retarder reached shore hardness 80 , the retarder shall be considered curing and formed bonded transfer mechanism.

Table 1 Retarder property of retard-bonded PC steel strands at different curing time

\begin{tabular}{|c|c|c|c|}
\hline specimens & $\begin{array}{c}\text { Curing time } \\
\text { /Days }\end{array}$ & $\begin{array}{c}\text { shore scleroscope } \\
\text { hardness D }\end{array}$ & Ratarder status \\
\hline 1 & 120 & 0 & Black viscous liquid \\
\hline 2 & 270 & 64.8 & Black solid, soft, \\
\hline 3 & 360 & 81.3 & Black solid, hard \\
\hline
\end{tabular}

\section{Test results of retard-bonded PC steel strands}

\section{Friction coefficient variation during tensioning process}

During tensioning PC steel strands of the No. 1 specimen process, the stress value of sensor on PC steel strands tensioning end shall be higher than that on anchor end. When tensioning control stress was held for $5 \mathrm{~min}$, the tensile force on tensioning end shall be $195.3 \mathrm{kN}$ and the force on anchor end shall be $190 \mathrm{kN}$. Because of retarder would have viscous, there is loading at anchor end of the PC steel strands when there is certain initial tensile force at tensioning end of the PC steel strands.

When the shore scleroscope hardness was 0 , the viscosity of retarder was so small that the tensile force would be transferred to anchor end quickly. Once the PC steel strand sliding was caused by disturbance, the stress difference between the two ends would be reduced gradually. The tensioning terminal stage would generally last for a long time period. at that time, the stress difference value of the two ends of the test specimen would be minimum, $k$ value shall be taken. From Fig. 5 (a) we could see, when tensioning end reached control stress, $k$ value was 0.0084 . 


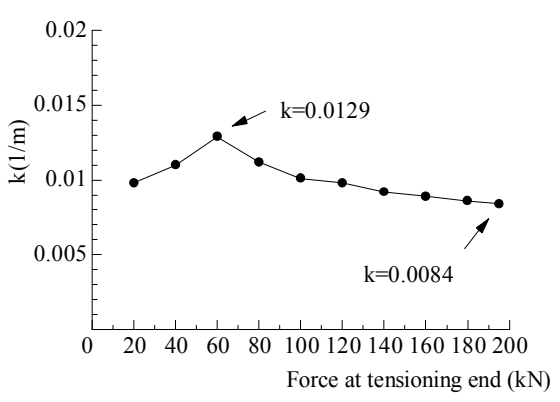

(a) No. 1 specimen

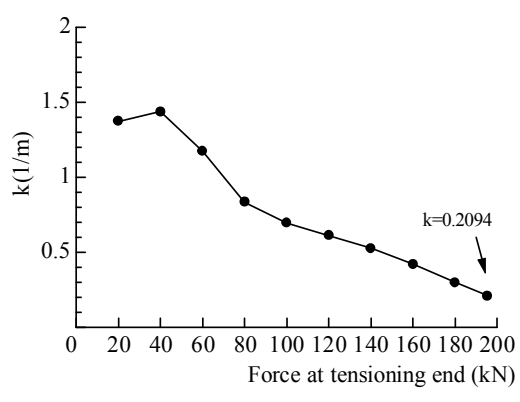

(b) No. 2 specimen

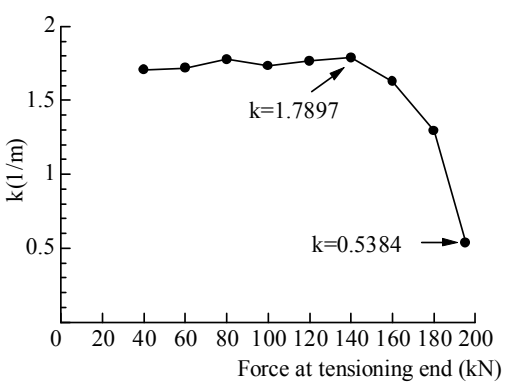

(c) No. 3 specimen

Fig. 5 Friction coefficient $k$ value line chart at tensile test

From Fig. 5(a), we could see that the $k$ value of No. 1 specimen has variation but is not obvious, the ascent stage was static friction coefficient. When $k$ value was 0.0129 , due to disturbance of retard-bonded PC structure, the curve would show a slow downward trend. Other specimen as a whole would also show a downward trend with the increase of $k$ value of tensile force.

\section{Influence of retarder curing degree to friction coefficient $k$ during tensioning}

When the PC steel strands were tensioned to control stress, the retarder curing degree, stress loss and friction coefficient $k$ were as shown in Table 2. From Table 2, it would found that the stress difference between the two ends would also increase during tensioning with the increase of retarder hardness. When PC steel strands reached control stress, stress difference between No. 1 specimen tensioning end and anchor end was small, and it would increase with increasing retarder hardness, stress loss would also increase gradually. With increase of retarder curing degree (shore hardness) during tensioning, stress loss and friction coefficient would increase. When tensioning No. 3 specimen, the shore hardness was 81.3 , stress loss reached $25.66 \%$, friction coefficient $k$ was 0.5384 .

Table 2 Friction loss and friction coefficient $k$ value for the PC steel strands

\begin{tabular}{|c|c|c|c|c|c|c|}
\hline specimen & $\begin{array}{c}\text { Tensioning shore } \\
\text { hardness }\end{array}$ & $\begin{array}{c}\text { Tensioning end } \\
\text { stress } F_{1} / \mathrm{kN}\end{array}$ & $\begin{array}{c}\text { Anchor end } \\
\text { stress } F_{2} / \mathrm{kN}\end{array}$ & $\begin{array}{c}F_{1}-F_{2} / \mathrm{k} \\
\mathrm{N}\end{array}$ & $\begin{array}{c}\text { Stress } \\
\text { loss } / \%\end{array}$ & $\mathrm{k} / \mathrm{m}^{-1}$ \\
\hline 1 & 0 & 195.3 & 190 & 5.3 & 2.7 & $\begin{array}{c}0.008 \\
4\end{array}$ \\
\hline 2 & 64.8 & 195.3 & 158.06 & 37.24 & 19.06 & $\begin{array}{c}0.209 \\
4\end{array}$ \\
\hline 3 & 81.3 & 195.3 & 145.18 & 50.12 & 25.66 & $\begin{array}{c}0.538 \\
4\end{array}$ \\
\hline
\end{tabular}

\section{Pre-stress loss variation of steel strands after tensioning}

Tensioning end and anchor end stress of the No. 1 specimen was Monitored after tensioning, and pre-stress loss variation of the PC steel strands was shown in Table 3. From Table 3, it was found that the value measured on the anchor end decreased with the increase of retarder curing time. Generally, it was found that the difference between the two ends would decrease with the growth of the retarder curing time and it would become stable after 109 days. 
Table 3 Stress loss and retarder curing time of the No. 1 specimen PC steel strands

\begin{tabular}{|c|c|c|c|c|}
\hline $\begin{array}{c}\text { Anchoring } \\
\text { time/day }\end{array}$ & Anchor end $F_{2} / \mathrm{kN}$ & Tensioning end $F_{1} / \mathrm{kN}$ & $F_{2}-F_{1} / \mathrm{kN}$ & $\begin{array}{c}\text { Pre-stress } \\
\text { loss } / \%\end{array}$ \\
\hline 1 & 151.03 & 143.29 & 7.74 & 5.13 \\
\hline 9 & 150.29 & 142.57 & 7.72 & 5.14 \\
\hline 19 & 149.26 & 141.86 & 7.41 & 4.96 \\
\hline 26 & 149.12 & 142.14 & 6.97 & 4.68 \\
\hline 42 & 148.68 & 141.86 & 6.82 & 4.59 \\
\hline 58 & 148.53 & 141.71 & 6.82 & 4.59 \\
\hline 90 & 147.21 & 140.43 & 6.78 & 4.60 \\
\hline 101 & 145.74 & 140.29 & 5.45 & 3.74 \\
\hline 109 & 145.59 & 140.29 & 5.30 & 3.64 \\
\hline 123 & 145.44 & 140.14 & 5.30 & 3.64 \\
\hline
\end{tabular}

\section{Conclusions}

(1) Under the same retarder curing degree, friction coefficient of PC steel strand would gradually decrease with the increases of tensile force.

(2) As stress of PC steel strands reached control stress, the friction coefficient would gradually increase with the increase of retarder hardness. And when retarder shore scleroscope hardness reached the value of 81.3 , the PC steel strands friction coefficient $\kappa$ increased to 0.5384 .

(3) The stress loss of PC steel strands was large upon completion of tensioning. The stress loss would decline gradually with the curing time increasing, and would tend to stable after 109 days.

\section{References}

[1] Zaiki Tsutomu, Minami Toshikazu etc. Various characteristics of After-Bond Pre-stressed Cable [J], Journal of pre-stressed concrete, Vol.32 (4) : 91-98 (1990) .

[2] Japan Road Association. Specification for highway bridges part III Concrete design [M], Japan, Tokyo, 2002.

[3] Liu Wenhua, Liu Lijun, Zhu Long etc. The Experimental Study of Retarding Adhesive Pre-stressed Steel Wire Strand [J], Architecture Technology, Vol.34 (12): 917-918. (2003).

[4] Wu Zhuanqin, Zeng Zhaobo, Shang Renjie etc. Experimental Study on Friction Coefficient of Retard-bonded Prestressing Strand [J], Industrial Construction, Vol.38 (11): 20-23. (2008).

[5] Shang Renjie, Zhang Qiang, Zhou Jianfeng etc, Experimental Study on Retard-bonded Pre-stressed Concrete Beams in Bending [J], Industrial Construction, Vol.38 (11): 24-27. (2008).

[6] Wu Zhuanqin, Shang Renjie, Hong Guang etc. Experimental Study on Cohesive Property Between Retard-bonded Pre-stressing Steel Strand and Concrete [J], Building Structure, Vol.43 (2): 68-70. (2013). 